\title{
ERRATUM
}

\section{Fluoxetine effects on molecular, cellular and behavioral endophenotypes of depression are driven by the living environment}

S Alboni, RM van Dijk, S Poggini, G Milior, M Perrotta, T Drenth, N Brunello, DP Wolfer, C Limatola, I Amrein, F Cirulli, L Maggi and I Branchi

Molecular Psychiatry (2017) 22, 635; doi:10.1038/mp.2015.191; published online 24 November 2015

Correction to: Molecular Psychiatry (2017) 22, 552-561; doi: 10.1038/mp.2015.142; published online 15 September 2015
In Table 1, the marker in the last column of the Stressful condition row should have been a $\uparrow$. The publisher regrets the error. 